\title{
ENTREVISTA
}

\section{MAÇONARIA E REPÚBLICA: confrontos, conflitos, tensões e atuação sociopolítica de maçons em Pernambuco nas décadas de 1930 e 1940}

El investigador Augusto César Acioly Paz Silva ${ }^{1}$ ha defendido una Tesis de Doutorado, cuyo título es "MAÇONARIA E REPÚBLICA: confrontos, conflitos, tensões e atuação sociopolítica de maçons em Pernambuco nas décadas de 1930 e 1940 " en la Universidad Federal de Pernambuco en Brasil, el Pernambuco². Augusto César Acioly Paz Silva nació en 25 de março de 1981 en Paulo Afonso, no estado da Bahia, no Brasil.

El autor nos ha concedido la siguiente entrevista.

¿Cuáles fueron los motivos que le llevó a enfocar su investigación hacia la Masonería?

O meu interesse pela Maçonaria surgiu por várias motivações, num primeiro momento, a partir de experiencias pessoais, na adolescencia participei de um grupo paramaçônico, denominado Ordem Demolay, a esta altura morava na cidade de Paulo Afonso, no interior da Bahia, onde nasci e cresci e me chamava a atenção a visão que os meus colegas construíam a respeito da Maçonaria, eivada claro, por visões esterotipadas e que dialogavam com todo aquele ideario antimaçônico. De alguma, forma, esta realidade me deixava inquietado e foi uma das motivações que ajudaram na escolha deste tema, aliado é claro ao desenvolvimento de um projeto de pesquisa de iniciação científica desenvolvido ao longo da graduação quando estudava as relações entre intelectuais católicos, Ação Integralista Brasileira, o proceso de Recristianização e a sociedade pernambucana, tendo como recorte temporal as décadas de 1930 e 1940. Diante deste cenário observei a construção de varios discursos que tinham como alvo a Maçonaria e forneciam um conjunto de visões negativas, algumas delas dialogando com o antimaçonismo do século XIX, fundado numa visão satânica e revolucionária da Maçonaria e outras baseadas, numa concenpção com contornos antisemitas, muito forte neste período. Quando concluía a graduação em História na Universidade Católica de Pernambuco, escolhi tomar como tema de pesquisa a Maçonaria preocupando-me em consturir um enfoque histórico, procurando assim, compreende-la no proceso de estruturação, enquanto instituição, no Brasil e

\footnotetext{
${ }^{1}$ Doutor em História pela UFPE, 2013. Professor do curso de História da Autarquia de Ensino Superior de Arcoverde e da Autarquia Educacional de Afogados da Ingazeira. E-mail: cesar historia@hotmail.com; cesarhistoriapibid@gmail.com

2 A tese pode ser lida na íntegra no seguinte endereço Web: http://www.repositorio.ufpe.br/bitstream/handle/123456789/11495/final $\% 20$ Tese $\% 20$ Vers $\% \mathrm{C} 3 \% \mathrm{~A} 3 \mathrm{o} \% 20 \mathrm{def}$
} 
Pernambuco, discutindo as suas "polémicas" com os intelectuais católicos e a Igreja Católica, este esforço procurava então, compreender e discutir quais motivos e a origem destes confrontos, além de compreender qual o lugar ocupado pela Maçonaria enquanto, tema histórico e historiográfico, são estas as questões que desde o meu mestrado venho procurando me ocupar.

¿Cuáles fueron las fuentes que ha utilizado?

As fontes que fomos coligindo ao longo da estruturação das nossas pesquisas, tanto no mestrado quanto no Doutorado se constituem, tanto em material produzido pelos próprios maçons como: revistas, jornais e de maneira inferior livros, por ele escritos. Como também, outro conjunto documental que se compõe daquilo que poderiamos caracterizar como fontes antimaçônicas, que tiveram na sua maior parte como produtores, os intelectuais católicos utilizando-se como espaço e difusão, os periódicos produzidos e mantidos por eles. Além destes trabalhamos na nossa tese com fontes que eram provenientes de órgaos de repressão do Estado, como no caso do Departamento de Ordem Política e Social do DOPS-PE, que no Brasil após 1937 foi responsável pelo fechamento e vigilancia das lojas maçônicas no País. Nos arquivos deste órgao encontramos alguns materiais que foram apreendidos e que mesmo após o fim do período de repressão no Brasil, que se iniciou em 1937 e finalizou em 1945, sob o governo de Getúlio Vargas e, em Pernambuco, tendo à frente Agamenon Magalhães, não foram devolvidos aos maçons. Trabalhamos também com alguns livros de memórias, produzidas por pessoas que viveram o período estudado, principalmente as décadas de 1930 e 1940. De forma geral, ao longo do desenvolvimento da pesquisa, o nosso conjunto documental se compôs destes acervos.

¿Cuáles fueron las principales dificultades con las que se ha encontrado? ¿Cómo las ha superado?

Acreditamos que ao longo da pesquisa um dos problemas encontrado foi o fato de que no Brasil infelizmente, não possuimos arquivos maçônicos mais bem sistematizados, muito disso devido à mentalidade que ainda encontramos em certos círculos maçônicos, de posição mais tradicional, que tende ao não ver com bons olhos uma pesquisa desenvolvida por "profanos". Mesmo encontrando no seio da Maçonaria outros grupos que não compartilham desta visão, acreditamos que a desorganização e falta de uma cultura arquivistica junto às agremiações maçônicas constituiem-se numa grande dificuldade. Porém, tivemos sorte, se assim podemos dizer, durante alguns momentos da nossa pesquisa, pois quando estavamos pesquisando antes de entrarmos no Mestrado encontramos 
uma coleção de revistas produzidas por maçons que cobria o período de 1909 até 1914, que se tornou o cerne do nosso trabalho de mestrado. Já no caso da tese as publicações e fontes que trabalhamos tinham um carater descontinuo, porque tinhamos números de jornais que tiveram uma única edição, e como estrategia para solucionar esta descontinuidade tivemos que adotar uma postura indiciaria, no sentido de a partir destas fontes produzir analises que procurassem reconstuir as lógicas e disputas enfrentadas pelos maçons ao longo das décadas de 1930 e 1940, para que fosse possível estabelecer uma reflexão onde estas descontinuidades das fontes não contaminassem a nossa narrativa histórica. Então desta forma, aliando uma leitura e análise rigorosa do nosso acervo documental com toques de imaginação histórica construimos as reflexões que se encontram na Tese.

¿Cuáles fueron las principales problemáticas históricas que su trabajo ha resuelto?

Acho que colocar a discussão histórica e historiográfica da Maçonaria no Brasil e mais específicamente em Pernambuco, já se constitui numa problemática interessante e ao mesmo tempo importante. Óbvio, que além desta questão geral, aspectos como a construção de intolerancias, a atuação sociocultural da Maçonaria, e compreender quais as estrategias e Cultura Política por ela desenvolvidas durante a Republica, período em que a historiografía brasileira e a produzida sobre a maçonaria questionam qual o seu papel, são problemáticas centrais que tem motivado as nossas investigações. No caso específico da nossa Tese, procuramos desconstruir a visão de que a Maçonaria com o advento da Republica tinha se tornado uma instituição fora do debate político, social e cultural, o que pudemos observar foi que ela reordenou as suas estratégias de ação, desenvolvendo um Cultura Política diferente daquela que ao longo do século XIX no Brasil era conhecida, ou seja, a de intervenção revolucionária e participante de movimentos políticos partidários. Foi possível observar que ela continuou a ter posições e veiculá-las do ponto de vista político, mostrando quais os seus pontos de defesa, retomando no caso das décadas de 1930 e 1940 , a defesa de valores democráticos e liberais, valores que com a ascensão dos idearios autoritários e totalitários que tomaram conta do mundo, passou a questioná-los. Seguindo esta lógica, pudemos então observar que a Maçonaria continuou difundido e combatendo questões que com a complexificação da sociedade brasileira, não era mais somente bandeira sua, mas passava a ser de outros atores políticos, culturais e sociais.

¿Por favor, podría resumir la esencia de su Tesis en dos líneas?

O centro das suas questões está na compreensão de quais foram as estrategias políticas adotadas pela Maçonaria ao longo das décadas de 1930 e 1940 em Pernambuco, tentando establecer vínculos com a realidade do Brasil do período. Desta forma, tentamos tomar 
como ponto de partida para as nossas análises a Tese proposta pelo historiador, Sérgio Buarque de Holanda, de que com a Proclamação da República e a difusão do Positivismo, enquanto ideário político, a Maçonaria havia perdido espaço e atuação no campo da política. É possível observar, ao longo do nosso trabalho, que esta visão não pode ser vislumbrada como conclusiva, uma vez que as práticas políticas assumidas por esta instituição foram se metamorfoseando, provocando uma mudança nas posturas por elas assumidas além de definir outros critérios e propostas para serem colocadas como pontos importantes de atuação pela Maçonaria. A definição em destacar as décadas de 1930 e 1940 para as nossas análises se deu a partir da observação que, enquanto instituição, ela continuava a propor questões e defender posições na sociedade, ao mesmo tempo em que, devido ao crescente grau de autoritarismo e intolerância, que tomaram conta dos Tempos de Agamenon Magalhães, a partir de 1937, a Maçonaria teve as suas ações, em Pernambuco, interditadas e sua voz e posições silenciadas

¿Cuáles fueron las lecciones, a todos los niveles, personal y profesional, que usted ha deducido de su experiencia investigativa?

Todo proceso de investigação na História contribui no amadurecimento intelectual e profissional, pois a partir das dificuldades surgidas do próprio desenvolvimento da pesquisa e do dialogo com as fontes, historiografía e a teoria, aprendemos um pouco mais no proceso de nos tornarmos historiadores, aspecto que só é possível de experenciar atravessando os questionamentos e provocações que vão aparecendo com o desenrolar da pesquisa seja ela um projeto de iniciação científica ou Tese de Doutoramento. Cada um destes niveis, só contibui na formação e consolidação do nosso crescimento pessoal e profissional.

\section{¿Ahora, cuáles son sus proyectos profesionales?}

Pretendemos continuar a desenvolver pesquisas ligadas ao tema da Maçonaria, atualmente estamos coordenando um projeto de iniciação a docência financiado por um órgao de fomento brasileiro, conhecido como CAPES, e que tem como fio condutor a relação entre história e cinema. Realizamos entre os meses de julho à outubro deste ano, algunas ações tendo a Maçonaria como tema, destacando a forma como ela foi tratada nos livros escolares e nas produções fílmicas. Utilizamos para isto, um documentário apresentando o desenvolvimento da instituição e o seu envolvimento nos varios movimentos políticos da história da América Latina. A nossa estratégia, seguindo a metodologia do citado projeto, foi a realização de uma aula-intervenção na Educação básica sobre a Maçonaria, que ocorreu numa escola parceira do projeto, após esta etapa exibimos o documentário numa sessão de cineclube, tendo como objetivo explorarmos as relações e mediações entre 
história e cinema. A partir desta experiencia junto com os bolsistas envueltos no projeto, produziremos um documentário sobre a Maçonaria. Este é um exemplo de projeto concreto que estamos desenvolvendo nos últimos meses, já com relação a propostas de longa duração pretendemos dá seguimento ao estudo da Maçonaria centrando os nossos intereses mais específicamente, nas décadas de 1950 até os anos 1970, preocupados ainda, com as questões relacionadas à maneira como a Maçonaria em Pernambuco, obvio que dialogando com o Nordeste e o Brasil, foi atuando do ponto de vista sociopolítico, observando as posições que ela foi ao longo deste período assumindo com relação aos mais variados temas, sendo uma maneira de compreender as imagens que ela ajudou a forjar e como a sociedade e a própria historiografía foi percebendo-a.

¿Quisiera destacar algún aspecto que no se ha contemplado y que usted consideraría digno de reseñar?

Quería destacar e reafirmar a importancia de um espaço como este, pois de alguma forma torna-se uma plataforma necessária e importante para que as pessoas que tem se dedicado ao estudo da Maçonaria nos últimos anos, possam encontrar, pela qualidade dos artigos produzidos e das discussões provocadas, um centro importante no fortalecimento de novas posibilidades de pesquisa.

Esta entrevista se efectúo de forma telemática el 31 de outubro de 2015.

Autores de la entrevista: Ricardo Martínez Esquivel e Yván Pozuelo Andrés, Director y Editor de REHMLAC+.

DOI: http://dx.doi.org/10.15517/rehmlac.v7i2.22766 